\title{
Clinical investigation of neonatal jaundice
}

\author{
Aliyu Muhammad ${ }^{1}$, Mansur Lawal ${ }^{2}$, Nathan Habila*¹, Wasagu R. S. Umar ${ }^{2}$ and Idowu A. \\ Aimola $^{1}$ \\ ${ }^{1}$ Department of Biochemistry, Ahmadu Bello University Zaria, Nigeria. \\ ${ }^{2}$ Department of Biochemistry, Usman Danfodio University, Sokoto, Nigeria.
}

Accepted 25 October, 2011

\begin{abstract}
Serum bilirubin levels of 93 neonates aged between 0 and 14 days were estimated. The bilirubin levels were determined spectrophotometrically at $570 \mathrm{~nm}$ (Direct) and $540 \mathrm{~nm}$ (Total) at the pediatric unit, Usmanu Danfodiyo University Teaching Hospital (UDUTH), Sokoto, Nigeria using continuous sampling techniques. It was established that the number of neonates with hyperbilirubinemia decreased with age. The mean concentration of direct, indirect and total bilirubin of jaundiced neonates were significantly elevated $(p<0.05)$ as compared to healthy neonates. There was, however, no significant different ( $p>0.05)$ in bilirubin levels between the age groups tested in this study. Neonatal Jaundice is a serious health problem concern with prolonged case that could be of grave or even fatal consequences. It is therefore pertinent from the result shown in this study that, close monitoring of bilirubin levels is essential during early infancy.
\end{abstract}

Key words: Bilirubin, neonates, jaundice, incidence age.

\section{INTRODUCTION}

Jaundice (also called icterus) refers to yellow colour of the skin and sclera (white of the eye) caused by deposition of bilirubin secondary to increase bilirubin level in the blood (Richard and Pemela, 1994). Neonatal jaundice is a common malady in new born infants. Although it is often a natural and transitional condition, some infants develop severe hyperbilirubinemia, in which unconjugated bilirubin in the serum may cross blood brain barrier and cause bilirubin encephalopathy (acute bilirubin intoxication) or kermicterus (chronic bilirubin intoxication) (Ichiro et al., 2010). Hyperbilirubinemia in the new born infant can only be managed in the neonatal ward. It is of concern that early discharged infants may develop extremely high bilirubin levels at home. However, when the infants at risk are identified in time they can remain in the neonatal ward and brain damage due to hyperbilirubinemia can be prevented. Therefore, it is a prerequisite to identify the infants at risk for developing severe hyperbilirubinemia (AAPSH, 2004). Similarly some genetic factors are associated with pathological conditions that may cause or aggravate neonatal jaundice.

\footnotetext{
*Corresponding author. E-mail: nathanhabila@yahoo.com.
}

A report has earlier shown that in Western Nigeria, Neonatal jaundice is a disorder that affects about $60 \%$ of the neonates seen in various Hospitals (Ransome-kuti, 1972). This statistic excludes other geographical location of Nigeria of which there is a vast variation in ethnicity and genetic polymorphism.

Nigeria is still a primarily rural country, with only $48 \%$ of its population living in cities. Urban areas, however, doubled their share of the population between 1970 and 2010. The country has a long history of urban development, particularly in northern Nigeria (Roberts and Peters, 2010). Nigerian society varies greatly between urban and rural areas, across ethnic and religious borders, and with levels of education. Still, most Nigerians share a strong attachment to family and especially to children. This investigation is however relevant in the far north of Nigeria where infant mortality is on the increase in spite of the increasing technological advancement. Ironically, poverty and other factors have also played a part in this malady. Northerners are also known to eat more meat, either in sauces or as kebabs known as tsire. Yogurt and soured milk produced by Fulani pastoralists form an important part of rural northern diets (Roberts and Peters, 2010).

To the best of our knowledge, the present study has not not been conducted to check the incidence of neonatal 
jaundice Northern Nigeria but to ascertain the relationship between jaundice and age.

Therefore, we report in this communication the incidence of neonatal jaundice and its relationship with age, bearing in mind the increasing population of the world.

\section{MATERIALS AND METHODS}

\section{Blood samples and reagents/chemicals}

Blood samples from ninety three (93) neonates (0-14days) were obtained from the pediatric unit, at Usmanu Danfodiyo University teaching Hospital (UDUTH), Sokoto, Nigeria between ages 0-14 days. The chemicals and reagents used were of analytical grades. The blood was collected by venous puncture and allowed to clot, centrifuged for $10-15 \mathrm{~min}$ at $1,500 \mathrm{rpm}$. The serum was collected by the use of pasture pipette and stored in the freezer at $4^{\circ} \mathrm{C}$ until required if the samples were to be stored for a relatively longer period before used, the sample bottles were wrapped with black carbon paper, so as to prevent oxidation of bilirubin.

\section{Determination of serum Bilirubin (Total and direct)}

A spectrophotometric modified method of Jendrassik and Grof (1938) of diazo coupling procedure was adopted for this study as described (Derek and Janice, 1961). It is based on the fact that direct bilirubin reacts with diazotized sulphanilic acid to form a blue colored complex in an alkaline medium. Total bilirubin is determined by the addition of caffeine which releases albumin bound bilirubin, by the reaction with diazotized sulphanilic acid.

\section{Calculation}

$\begin{array}{lll}\text { Total bilirubin }(\mathrm{mg} / \mathrm{dL}) & = & 10.8 \times \mathrm{A}_{\mathrm{TB}}(570 \mathrm{~nm}) \\ \text { Direct bilirubin }(\mathrm{mg} / \mathrm{dL}) & = & 14.4 \times \mathrm{A}_{\mathrm{DB}}(540 \mathrm{~nm}) \\ \text { Indirect bilirubin }(\mathrm{mg} / \mathrm{dL}) & = & \text { Total }- \text { Direct }(\mathrm{mg} / \mathrm{dL}) \\ \text { Sample size } & =93 \text { neonates }\end{array}$

Reference range of serum bilirubin

Total bilirubin

$\begin{array}{lll}0-7 \text { days } & = & \text { up to } 5.0 \mathrm{mg} / \mathrm{dL} \\ 8 \text { days and above }= & \text { up to } 1.2 \mathrm{mg} / \mathrm{dL} \\ \text { Direct bilirubin }= & \text { up to } 0.25 \mathrm{mg} / \mathrm{dL}\end{array}$

\section{RESULTS AND DISCUSSION}

The result in Table 1 shows the mean concentration of direct, indirect and total bilirubin of the Neonates across ages and infection. Mean concentration of bilirubin were statistically but not significant ( $p>0.05)$ across all ages. Whereas Means concentration of bilirubin across jaundiced neonates were statistically significant $(p<0.05)$ when compared healthy Neonates.

The result in Table 2 shows the percentages of jaundice of Neonates across ages: $0-3,4-7$ and 8-14 days. During the study, 93 neonates were used of which 33 were for $0-3$ days, 30 for $4-7$ days and 30 for $8-14$ days. From it, $93.94 \%$ of the first categories were jaundiced, $86.67,83.33 \%$ for second and third categories were also jaundiced respectively. However, the number of jaundiced Neonates decreases with increase in ages.

\section{DISCUSSION}

Neonatal jaundice is a common peadiatric problem in West Africa (Sofoluwe and Gans, 1960). This condition is associated with high morbidity and mortality. It has been reported that the condition is the commonest cause of neonatal admission to the children's especially in the emergency room (Ransome kuti, 1972). Attention has also been drawn to the importance etiologic role of neonatal jaundice in cerebral palsy among Nigerian Children (Animashawn, 1971; Ransome Kuti, 1972). Under normal circumstances, the level of bilirubin rises at birth and signs of jaundice becomes visible, usually peaking between the 2nd and 4th day. However, the levels start to decrease between the 6th and 8th days of life (Beebe et al., 1994). This type of jaundice is referred to as physiological and may result from defective transport of bilirubin into hepatocyte (Huang and Kuake, 2004 and Prachukthum et al., 2009) low activity of bilirubin conjugating enzyme (Mushi et al., 2008) excessive load of bilirubin to liver than it can conjugate due to its immaturity at birth as a result of Homolysis from blood type in compatibilities (John and Candlish, 1977).

However, if Jaundice persists after the third day of life, this may suggest a severe form of hyper bilirubinemia. If the bilirubin level continues to rise, a mere acute of jaundice like kernicterus and cerebral palsy results (Beebe et al., 1994). From Table 1, the mean concentration of direct indirect and total bilirubin of jaundice neonate among infant were significant $(P<0.05)$ when compared with normal neonates. This is in line with finding of Johnson (1993) that, jaundice is common. There was however no significant $(P>0.05)$ difference in bilirubin levels in all ages considered. The resulting indication that the percentage of neonates with jaundice rises as from 0-3 days and gradually starts decreasing with age is obvious. This is consistent with the report of American Academy of paediatric that neonatal jaundice affect $60 \%$ of full term infants and $80 \%$ of preterm infants in the first three days after birth, and the percentage gradually decreases with age, with the exception of a few who were conformed jaundiced due to other reason. The severity of hyperbilirubinemia is presented in Table 2 of which none of the infants have a risk of developing kernicterus. This is because kernicterus rarely occurs with bilirubin level lower than $20 \mathrm{mg} \%$, but typically occurs when the level exceeds $30 \mathrm{mg} \%$. Also, when the bilirubin 
Table 1. Serum bilirubin levels across age categories versus jaundiced and normal in infant.

\begin{tabular}{lccc}
\hline \multirow{2}{*}{ Treatment } & \multicolumn{3}{c}{ Bilirubin mean \pm standard error of the mean $(\mathbf{m g} / \mathbf{d L})$} \\
\cline { 2 - 4 } Age (days) & Direct & Indirect & Total \\
0-3 & & & \\
$4-7$ & $2.4985 \pm 0.5419^{\mathrm{a}}$ & $5.5455 \pm 0.9907^{\mathrm{a}}$ & $8.4006 \pm 0.6882^{\mathrm{a}}$ \\
$8-14$ & $3.7880 \pm 0.6419^{\mathrm{a}}$ & $7.0193 \pm 0.8707^{\mathrm{a}}$ & $10.8540 \pm 0.7882^{\mathrm{a}}$ \\
& $4.0483 \pm 0.4419^{\mathrm{a}}$ & $5.8203 \pm 0.8907^{\mathrm{a}}$ & $9.6153 \pm 0.9882^{\mathrm{a}}$ \\
Jaundiced/Normal & & & \\
Jaundice & & & \\
Normal & $3.8995 \pm 0.0406^{\mathrm{a}}$ & $6.9890 \pm 0.0743^{\mathrm{a}}$ & $12.4700 \pm 0.5471^{\mathrm{a}}$ \\
\hline
\end{tabular}

Within a treatment group, mean \pm standard errors in column followed by same letters are not significantly different, using Lsd at $5 \%$ level.

Table 2. Percentage incidence of neonatal Jaundice.

\begin{tabular}{cccc}
\hline Age (days) & Total number of Neonates $(\mathbf{n})$ & Number that have jaundice $(\mathbf{x})$ & $\frac{\boldsymbol{x}}{\boldsymbol{n}} \times \mathbf{1 0 0} \%$ \\
\hline $0-3$ & 33.00 & 31.00 & 93.94 \\
$4-7$ & 30.00 & 26.00 & 86.67 \\
$8-14$ & 30.00 & 25.00 & 83.33 \\
\hline
\end{tabular}

levels are between $20-30 \mathrm{mg} \%$, conditions such as prematurity and hemolytic disease may increase the risk of kernicterus (Maisels , 1995).

\section{Conclusion}

This study has demonstrated that jaundice is common among infants and thus, hyperbilirubinemia should be identified early and promptly treated, in order to reduce infants' morbidity and mortality as well as the risk of kernicterus and cerebral palsy in the survivors.

\section{REFERENCES}

American Academy of Padiatrics subcommittee on Hyperbolirubinemia, (AAPSH), (2004). Management of Hyper bilirubinemia in the new born infant 35 or more weeks of gestation. Paediatrics, 114: 297-316.

Animashau A (1971). Astiology of Cerebral palsy in African Children. Afr. J. Med. Sci., 2: 165.

Beebe SA, Britton JR, Britton HL (1994). Early discharge of the term newborn; a Continued Dellema Pediatrics, 94(3): 291-295.

Derek W, Janice AR (1961). A study of six representative methods of plasma bilirubin analysis, J. Clin. Path., 14: 271.
Huang MJ, Kuake THC (2004). Risk factors for severe hyporbilirubinemia in noenates. Paediatric Res., 56: 682-689.

Ichiro M, Satoru M, Suririn Y (2010). Genetic disorders associated with nomatal jaundice, Review article, Easter J. Med., 15: 155.

Jendrassik L, Grof P (1938). Bilirubin estimation Biochem Z. 297:81.

John KC, Candlish (1977). A medical biochemistry for tropics, Macmillan London; pp. 132-136.

Johnson JD (1993). Exaggerated Jaundices in Nauago neonates; the role of bilirubin production Am. J. Dis. Child., 140: 889-890.

Maisels MJ (1995). Kernicterus in otherwise healthy breast fed form new borns, Paediatric, 96 (4PH): 730-733.

Mushi N, Dogruer ZN, Kandari ESG (2008). Are Glutathione transferase gene polymorphisms linked to neonatal jaundice? Eur. J. Paediatrics, 167: 57-61.

Prachukthum S, Nunnarumit P, Pienvichit P (2009). Genetic polymorphism in thai neonates with hyperbilirubinemia. Acta Paediatrics, 98: 1106-1110.

Ransome-Kuti O (1972). The problems of paediatric Emergencies in Nigeria. Nigeria Med. J., 2: 62.

Richard A, Pamela C (1994). Lippincotts illustrated review of Biochemistry, $2^{\text {nd }}$ ed, Williams and Wilkins. pp. 237-64.

Sofoluwe GO, Gans B (1960). Neonatal Jaundice in Lagos, Wr. Afr. Med. J., 9:145. 